\title{
Evaluation of the psychometric properties of the Persian version of the Pittsburgh Sleep Quality Index in depressed patients
}

\author{
Shahrzad Khosravifar ${ }^{1}$, Mirfarhad Ghaleh Bandi ${ }^{2}$, Kaveh Alavi ${ }^{3}$, Pariasadat Haj Seied Javadi ${ }^{4}$
}

${ }^{1}$ Residence of Psychiatry, Department of Mental Health and Psychiatry, Iran University of Medical Sciences, Tehran, Iran

${ }^{2}$ MD, Associate Professor of Psychiatry, Sleep Medicine Fellowship, Department of Psychiatry, Mental Health Research Center, Iran University of Medical Sciences, Tehran, Iran

${ }^{3}$ Department of Mental Health and Psychiatry, Iran University of Medical Sciences, Tehran, Iran

${ }^{4}$ Residence of Psychiatry, Department of Psychiatry, Tehran University of Medical Sciences, Tehran, Iran

Type of article: Original

\begin{abstract}
Introduction: The Pittsburgh Sleep Quality Questionnaire is capable of covering different stages of sleep, and it is regarded as one of the best ones available, and checking for its validity and reliability among depressed patients is a step in this direction. The aim of this study was to evaluate the reliability and validity of the Persian version of the Pittsburgh Sleep Quality Index (PSQI) and Epworth Sleepiness Scale (ESS) questionnaires in patients with depression.

Methods: In this study, 93 depressed patients were in the study group, and 100 patients were in the control group. The Persian translation of the PSQI and ESS questionnaires and the Beck Depression Inventory (BDI) were at the disposal of both validity and reliability of PSQI and ESS, and its correlation with BDI scores were analyzed.

Results: In our study, Cronbach's alpha coefficient of the PSQI questionnaire was 0.821 . According to the PSQI and BDI-II scores, the results between the PSQI and ESS scores were significantly correlated.

Conclusion: Using the Persian PSQI and ESS questionnaires to evaluate sleep quality and daytime sleepiness in patients with depression provides a reliable and valid measure for subjective sleep quality in clinical practice and research.
\end{abstract}

Keywords: psychometric properties, Persian, Pittsburgh Sleep Quality Index (PSQI), depression

\section{Introduction}

Sleep disturbance is associated with many complications and decreased efficiency during the day, increased somnolence and reaction time, and reduced power of making correct and timely decisions (1). Sleep and poor quality sleep can result from physical discomfort and be a side effect of drugs and mental disorders, such as depression, anxiety, and schizophrenia (1). Ohayon \& Reynolds (2), in their 2009 study, showed that half of the patients with sleep disorders also had some symptoms of a mental disorder, such as anxiety, and mood disorders, but depression was the most frequent one. The distorted night sleep symptoms in depressed patients have been described extensively in clinical trials. Major depressive disorder (MDD) is a mental state characterized by depressed mood, loss of energy, loss of interest in usual activities, anhedonia, and unrealistic negative thoughts about oneself, the future, and social isolation (3). The median 12-month prevalence of MDD in 42 studies in various countries was reported to be $5.3 \%$ by a recent review (4). In addition, depressive disorders cause a significant negative impact on daily functioning (5). It is usually a matter of several common scales for MDD associated with sleep problems (6). The prevalence of sleep disturbances in patients with MDD has been reported to range from 10 to $60 \%$. It varies because of various definitions of sleep disturbances and data-collection methodologies (7). The association between sleep disturbances and MDD was reported that $41 \%$ of depressed patients had sufficient insomnia for an additional

\section{Corresponding author:}

Associate Professor Dr. Mirfarhad Ghaleh Bandi, Sleep Medicine Fellowship, Department of Psychiatry, Mental Health Research Center, Iran University of Medical Sciences, Tehran, Iran.

Tel: +98.9121883406, E-mail: mirfarhadg@yahoo.com

Received: July 06, 2015, Accepted: August 21, 2015, Published: December 2015

iThenticate screening: August 21, 2015, English editing: November 02, 2015, Quality control: November 10, 2015

(C) 2015 The Authors. This is an open access article under the terms of the Creative Commons Attribution-NonCommercialNoDerivs License, which permits use and distribution in any medium, provided the original work is properly cited, the use is non-commercial and no modifications or adaptations are made. 
DSM-IV diagnosis of insomnia (8). Ford et al. in their study showed that $14 \%$ of patients with persistent insomnia suffered from depression at the same time (9), and another study reported that $11 \%$ of the patients in a sleep clinic had major depression (10). In addition, Lundt showed that there was a relationship between severity of sleepiness and severity of depression (11). Therefore, it was suggested that sleep disturbances could be a potential marker for MDD. Sleep disorders can be used to explain many cognitive damages associated with depression, including negative or threatening interpretations regarding ambiguous stimuli (12). Chronic sleep deprivation can increase the stress response as well (13), which is one of the strongest and most reliable findings in depression. All of this evidence indicates that damage from sleep should be considered as a risk factor in the development of depression. Despite the importance of sleep disorders in depression diagnosis and being in fact one of the most important symptoms of depression, because of our lack of understanding, it has always been ignored in treatment. As a result, many cases are not diagnosed with sleep disorders and remain untreated. One reason for this is the fact that few tools exist to accurately measure the quality of sleep that can be used to better detect disorders found in this field (14). One of the widely used scales for sleep quality is the Pittsburgh Sleep Quality Index (PSQI). Pittsburgh Sleep Quality Questionnaire, which is used to evaluate sleep latency, sleep duration, and habits leading to good quality sleep, includes some components that deal with sleep disorders, medications, reduction in efficiency of daily performance, where total scores resulting from the study of these seven components provide a picture of quality and quantity of one's sleep (15). The Epworth Sleepiness Scale (ESS) Sleep Test Questionnaire also is used to measure daytime sleepiness and a guide to sleep problems and sleep disorders. Unlike the present study, that is evaluating Psychometric Properties of the Persian Translation of the Pittsburgh Sleep Quality Index in depressed patients, Morteza Nazifi and his colleagues studied staff working at the healthcare for this feature in a wider range (16). Since the Pittsburgh Sleep Quality Questionnaire is capable of covering different stages of sleep, it is regarded as one of the best ones available, and checking for its validity and reliability amongst depressed patients is a step in this direction. In view of limitations of sample size or studied population in previous psychometric studies $(16,19,25-$ 27), the need for a PSQI study with a larger sample of depressed patients was needed. So, the current study is concentrated on the reliability and validity of a special instrument to measure sleep quality (PSQI). The aim of this study was to determine the reliability and validity of the Persian version of the Pittsburgh Sleep Quality Index (PSQI) and the Epworth Sleepiness Scale (ESS) questionnaire in patients with depression.

\section{Material and Methods}

\subsection{Study setting and sampling}

In this case-control study that was carried out in 2014, 93 patients referred to outpatient clinics of Rasoul Akram and Iran Hospital, and Tehran Psychiatric Institute who were diagnosed with unipolar depression (MDD), bipolar type one (BID) or two (BIID) and dysthymia based on the Structured Clinical Interview for DSM Disorders (SCID), were enrolled in the study after obtaining their informed consent. Also, 100 healthy participants enrolled in the study as the control group.

\subsection{Data Collection Instrument}

The Pittsburgh Sleep Quality Index includes seven components of subjective sleep quality, sleep latency, sleep duration, sleep efficiency, sleep disturbances, the use of sleep medications and day time dysfunctions provide a total score of these seven components that allows us to better understand the quality and quantity of one's sleep. The Pittsburgh Sleep Quality Index is a self-reporting instrument consisting of nine questions designed to measure the quality of sleep disorders in a period of one month. The scale scores range from 0 to 21 , with higher scores indicating poor quality of sleep and scores less than 5 considered as high quality of sleep (15). The index is a summarized, accessible, and reliable tool for measuring sleep quality that has high internal consistency (Cronbach alpha $=0.83)$ and test-retest reliability $(0.85-0.87)$. It also means people with poor and high sleep quality with diagnostic sensitivity of 0.89 (coefficient of Kapa $=0.75, \mathrm{p}<0.001$ ), respectively (15). In addition, Epworth Sleep Scale (ESS), which is a subjective rating scale, was used to measure levels of daily sleep. This scale is also used to determine people with too much uneven sleep. Respondents are required to score the possibility of falling asleep in eight situations in their daily lives on a scale from 0 (never) to 3 (high risk of sleep). The scale scores range from 0 to 24, and a higher score means more irregular sleep. Epworth Sleep Scale (ESS) has been used widely to measure daytime sleepiness in older populations. Test-retest reliability and internal consistency of this scale is very high. In addition, patients with sleep disorders had significantly higher scores on this scale than the control group (17). Beck Depression Inventory-2, is suitable for people who are more than 13 years old and have at least a sixth-grade education. The questionnaire contains 21 indicators, all of which are related to the symptoms of major depression, and it is designed to check the status of emotion, cognition, obvious behavior, physical signs and symptoms of internal scale from lowest to highest marks allocated. At this scale, zero to nine levels indicate normal depression, 
scores of 10 to 16 indicate symptoms of mild depression, 17 to 29 indicate moderate depression, and scores of 30 or greater are indicative of severe depression (18). The Persian versions of two sleep questionnaires that used Pittsburg Sleep Quality Index (PSQI) and Epworth Sleepiness Scale (ESS) were used in previous studies (19).

\subsection{Research Procedure}

First, the patients with a diagnosis of unipolar, bipolar, major depression, or dysthymia based on Structured Clinical Interview (SCID) were selected, and they responded to the Brief Symptom Inventory of depression scale and Beck Depression Inventory-2, then the Persian version of the Pittsburgh Sleep Quality Index questionnaire was distributed to them, and results were compared with the Pittsburgh Sleep Quality Index questionnaire, completed by a control group of 190 people selected from the staff of the Tehran Institute of Psychiatry to assess the reliability and validity in this population. At the same time, patients were also assessed for daytime sleepiness with ESS questionnaire. Since results of this questionnaire can be effective in this study and, in particular, because daytime sleepiness and cognitive impairment caused by it could produce anxiety and depression and also intensify anxiety and depression in these people. Therefore, it was necessary to translate the English version into Farsi and then translate it back into English, and, at the same time, the reliability and validity of the questionnaire in this population could be examined. Inclusion criteria of study were diagnosis of unipolar depression, bi-polar, or dysthymia through a structured clinical interview and lack of co-morbidity with other diagnoses, both male and female genders, having knowledge of at least reading and writing. Exclusion criteria of the study were having other disorders associated with medical and chronic psychiatric and physical disorders, pregnancy, having two jobs with a night shift or a night shift job, medical drugs, or substance abuse.

\subsection{Data analysis}

We used the Pearson coefficient to determine test-retest reliability, and Cronbach's alpha was used to determine the reliability of the test. Confirmatory factor analysis was used to determine the actual structure of the scale and to determine the validity of the instrument. We also used the t-test to compare the difference between the two means of all quantitative variables in both the healthy and depressed groups.

\section{Results}

\subsection{Sociodemographic characteristics}

In this study, 93 depressed patients and 100 patients in the control group were examined. The mean age of depressed patients was $32.3(\mathrm{SD}=7.1)$, and their ages ranged from 21 to 61 (median: 30$)$, and the average age in the control group was $34.2(\mathrm{SD}=9.8)$, with people's ages in the range of 18 to 62 (median: 32$)$. In depressed patients' group, 34 women (36.6\%) and 59 men (63.4\%) and 66 women in the control group (66.0\%) and 34 males (34.0\%) were enrolled. Demographic details of people surveyed are given in Table 1.

Table 1. Demographic characteristics of the sample $(n=93)$

\begin{tabular}{|c|c|c|c|c|c|}
\hline \multicolumn{2}{|l|}{ Variables } & \multicolumn{2}{|c|}{$\begin{array}{l}\text { Patients with } \\
\text { depression }\end{array}$} & \multicolumn{2}{|c|}{ Control group } \\
\hline & & $\mathrm{n}$ & $\%$ & $\mathrm{n}$ & $\%$ \\
\hline \multirow{2}{*}{ Gender } & Female & 34 & 36.6 & 66 & 66.0 \\
\hline & Male & 59 & 63.6 & 34 & 34.0 \\
\hline \multirow[t]{3}{*}{ Education } & Under high school diploma & 33 & 35.3 & 7 & 7.0 \\
\hline & High school diploma & 45 & 48.8 & 44 & 44.0 \\
\hline & University & 15 & 16.1 & 49 & 49.0 \\
\hline \multirow[t]{4}{*}{ Marital status } & Single & 27 & 29.0 & 39 & 39.0 \\
\hline & Married & 48 & 51.6 & 57 & 57.0 \\
\hline & Divorced or separated & 11 & 11.8 & 3 & 3.0 \\
\hline & Unclear & 7 & 7.5 & 1 & 1.0 \\
\hline \multirow[t]{5}{*}{ Occupation } & Jobless & 65 & 69.9 & 5 & 5.0 \\
\hline & Steady and daily job & 17 & 18.3 & 66 & 66.0 \\
\hline & Part-time job, shifts, and others & 4 & 4.3 & 1 & 1.0 \\
\hline & Steady daily work with long hours & - & - & 27 & 27.0 \\
\hline & Unclear & 7 & 7.5 & 5 & 5.0 \\
\hline $\begin{array}{l}\text { Psychological } \\
\text { disorder record }\end{array}$ & Yes & 37 & 39.8 & - & - \\
\hline
\end{tabular}




\subsection{Analysis of the Pittsburgh Sleep Quality Index (PSQI) Questions}

- Question no. 1: Time to bed

Twenty (21.5\%) of those went to bed between 20 and 22 as their bed time. Forty-seven people $(50.4 \%)$ went to bed between 23 and 24 , and 26 of them $(28.0 \%)$ said that they go to bed between the hours of 1 and 4:00 A.M.

- Question no. 2: Time between going to bed and falling into sleep

An average of 40 minutes $(\mathrm{SD}=35)$ passed before the subjects went to sleep after getting into bed. The average time took 30 minutes and in a range of 0 to 180 minutes. Based on the PSQI encoding, 16 patients (17.2\%) received Code 0 (under 15 minutes), 43 (46.2\%) Coded 1 (between 16 and 30 minutes), 24 (25.8\%) Coded 2 (31 to 60 minutes) and 10 (10.8\%) Coded 3 (over 60 minutes).

- Question no. 3: Wake-up time

As shown in Table 2, most people woke up between 6:00 and 8:00A.M.

- Question no. 4: Amount of night sleep

Average hours of night sleep amongst those surveyed was 7.6 hours $(\mathrm{SD}=2.3)$ and in the range of 3 to 12 hours (median 6 hours) (Table 3).

- Question no. 5: Sleep problems

Table 4 describes sleep problems based on the fifth question in the Pittsburgh Sleep Quality Index (PSQI) in depressed patients surveyed.

Table 2. Wake-up hours in depressed surveyed people $(\mathrm{n}=93)$

\begin{tabular}{|l|l|l|}
\hline Wake-up hour & Frequency & Percent \\
\hline Before 6:00 A.M. & 15 & 16.1 \\
\hline 6:00 A.M. & 32 & 34.4 \\
\hline 7:00 A.M. & 16 & 17.2 \\
\hline 8:00 A.M. & 6 & 6.5 \\
\hline Between 9 to 11:00 A.M. & 21 & 22.6 \\
\hline 12:00 P.M. to 14:00 P.M. & 3 & 3.2 \\
\hline
\end{tabular}

Table 3. The amount of night sleep of depressed patients evaluated $(\mathrm{n}=93)$.

\begin{tabular}{|l|l|l|l|}
\hline Sleep duration & PSQI Code & Frequency & Percent \\
\hline More than 7 hours & Code 0 & 32 & 34.4 \\
\hline 6-7 hours & Code 1 & 9 & 9.7 \\
\hline 5-6 hours & Code 2 & 39 & 41.9 \\
\hline Less than 5 hours & Code 3 & 13 & 14.0 \\
\hline
\end{tabular}

PSQI: Pittsburg Sleep Quality Index

Table 4. Sleep problems based on the fifth question in the Pittsburgh Sleep Quality Index (PSQI) in depressed patients surveyed $(\mathrm{n}=93)$. The number in parentheses is the frequency.

\begin{tabular}{|l|l|l|l|l|l|}
\hline $\begin{array}{l}\text { Question } \\
\text { No. }\end{array}$ & Trouble in sleeping & $\begin{array}{l}\text { Not happened during } \\
\text { the past month } \\
\text { (code 0) }\end{array}$ & $\begin{array}{l}\text { Less than once } \\
\text { in month } \\
\text { code 1) }\end{array}$ & $\begin{array}{l}\text { Once or twice } \\
\text { in a week } \\
\text { (code 2) }\end{array}$ & $\begin{array}{l}\text { Three times or } \\
\text { more in a } \\
\text { week (code 3) }\end{array}$ \\
\hline $5 \mathrm{a}$ & $\begin{array}{l}\text { A distance of more than } \\
\text { half an hour to fall asleep }\end{array}$ & $19(20.4)$ & $25(26.6)$ & $26(28)$ & $23(24.7)$ \\
\hline $5 \mathrm{~b}$ & $\begin{array}{l}\text { Waking up at midnight or } \\
\text { early morning }\end{array}$ & $18(19.4)$ & $32(34.4)$ & $15(16.1)$ & $28(30.1)$ \\
\hline $5 \mathrm{c}$ & $\begin{array}{l}\text { The need for the } \\
\text { bathroom }\end{array}$ & $53(7)$ & $19(20.4)$ & $11(11.8)$ & $10(10.8)$ \\
\hline $5 \mathrm{~d}$ & Breathing problems & $65(69.9)$ & $16(17.2)$ & $10(10.8)$ & $2(2.2)$ \\
\hline $5 \mathrm{e}$ & Coughing or snoring long & $67(72)$ & $9(9.7)$ & $8(8.6)$ & $9(7.9)$ \\
\hline $5 \mathrm{f}$ & Feeling cold & $68(1.73)$ & $14(1.15)$ & $5(4.5)$ & $6(5.6)$ \\
\hline $5 \mathrm{~g}$ & Feeling hot & $50(8.53)$ & $21(6.22)$ & $13(0.14)$ & $9(7.9)$ \\
\hline $5 \mathrm{~h}$ & Having distorted dreams & $51(8.54)$ & $19(4.20)$ & $12(9.12)$ & $11(8.11)$ \\
\hline $5 \mathrm{i}$ & Other problems & $52(9.55)$ & $20(5.21)$ & $7(5.7)$ & $14(1.15)$ \\
\hline
\end{tabular}


- Questions no. 6-8

These questions examined the medications used to help patients sleep and daily functioning disorders based on the Pittsburgh Sleep Quality Index (PSQI) in depressed patients (Table 5).

- Question no. 9: Sleep quality

In this question, respondents were asked to rank the quality of their sleep in the past month. Six patients $(6.5 \%)$ indicated the quality of their sleep as very good, 37 (39.8\%) recognized it as relatively good, $37(39.8 \%)$ knew it as relatively poor, and $13(14.0 \%)$ described it as very bad.

Table 5. taking medication to help with sleep and daily functioning disorders based on the Pittsburgh Sleep Quality Index (PSQI) in depressed patients surveyed $(\mathrm{n}=93)$. The number in parentheses is the frequency.

\begin{tabular}{|l|l|l|l|l|l|}
\hline $\begin{array}{l}\text { Question } \\
\text { No. }\end{array}$ & Title & $\begin{array}{l}\text { Not happened during } \\
\text { the past month } \\
\text { (code 0) }\end{array}$ & $\begin{array}{l}\text { Less than once } \\
\text { in a week (code } \\
\text { 1) }\end{array}$ & $\begin{array}{l}\text { Once or twice } \\
\text { in a week (code } \\
\text { 2) }\end{array}$ & $\begin{array}{l}\text { Three times or } \\
\text { more in a week } \\
\text { (code 3) }\end{array}$ \\
\hline 6 & $\begin{array}{l}\text { Taking medication } \\
\text { to help sleep }\end{array}$ & $46(5.49)$ & $20(5.21$ & $14(1.15)$ & $13(0.14)$ \\
\hline 7 & $\begin{array}{l}\text { Difficulty in staying } \\
\text { awake during daily } \\
\text { routines }\end{array}$ & $40(0.43)$ & $26(0.28)$ & $19(4.20)$ & $8(6.8)$ \\
\hline 8 & Feeling energized & $11(8.11)$ & $44(3.47)$ & $25(9.26)$ & $13(0.14)$ \\
\hline
\end{tabular}

\subsection{PSQI components}

Parts 1, 2, 3, and 6 of PSQI questionnaire are described under questions 9, 2, 4, and 6, respectively. The fourth part measures proportion of time in bed compared with sleeping hours. The average percentage of sleep efficiency, as defined by the fourth component of PSQI was $90.0 \%(\mathrm{SD}=8.2)$ and in the range of 60 to $100 \%$ (median $92.3 \%$ ). Seventy-seven patients $(28.4 \%)$ had a sleep efficiency higher than $85 \%$ (coded 0$)$. Sleep efficiency of $11(11.8 \%)$ was between 75 and $84 \%$ (code 1). Three patients (3.2\%) had it between 65 and $74 \%$ of sleep efficiency (code 2 ) and in 2 patients $(2.2 \%$ ), sleep efficiency was less than $65 \%$ (code 3 ). The fifth component is the sum of the scores of questions $5 \mathrm{~b}$ to $5 \mathrm{j}$. Average raw score of people was about $6.8(\mathrm{SD}=5.3)$. Five patients $(5.4 \%)$ received Code 0 (score of 0 ), while 69 patients ( $74.2 \%$ ) were coded 1 (Grades 1 to 9), 13 people (14.0\%) coded 2 (Grades 10 to 18 ), and 6 people (6.5\%) coded 3 (Grades 19 to 27), respectively. The seventh component was the sum of questions 7 and 8. Eight patients (8.6\%) received Code 0 (score of 0 ), 46 people (49.5\%) Coded 1 (Grades 1 or 2), $30(32.3 \%)$ Coded 2 (grades 3 or 4 ) and 9 people (9.7\%) Coded 3 (Grades 5 or 6 ), respectively.

\subsection{PSQI total score}

The mean of PSQI total score of surveyed people was $8.1(\mathrm{SD}=3.5)$, which was in the range of 1 to 18 , and thus, only $12(12.9 \%)$ did not receive a score of less than 5. Percentiles 25,50 (middle), and 75 consisted of 6,8 and 10 , respectively. The mean PSQI score in the control group was 5.6 $(\mathrm{SD}=3.1)$, and in the range of 0 to 15 , which was significantly lower than that of depressed patients $(t=5.142, \mathrm{p}<0.001)$. In this group, 37 patients $(37.0 \%)$ had a score below 5 and percentiles 25,50 , and 75 consisted of 3,5 , and 7 , respectively.

\subsection{Internal consistency}

Cronbach's alpha coefficient of the questionnaire for 16 titles (regardless of questions 1 and 3 ) and with regard to coding of questions 2 and 4 was 0.811 . With the elimination of the fourth question, this index would increase up to $0.821(\mathrm{p}=0.002)$.

\subsection{Correlation with Other Questionnaires}

Average scores of people on the Beck Depression Inventory (BDI-II) was $27.1(\mathrm{SD}=10.2)$ and $18.0(\mathrm{SD}=3.8)$ for Epworth Sleep Scale (ESS). The Pearson correlation coefficient was $0.299(\mathrm{p}=0.004)$ between scores of PSQI and $0.264(\mathrm{p}=0.011)$ between ESS and PSQI.

\subsection{Factorial Structure of PSQI}

In order to do the exploratory factor-analysis of the questionnaire, principal component and Oblimin rotation were used. The KMO index of 0.598 and Bartlett test of sphericity were statistically significant $(\mathrm{p}<0.001)$, which showed the relative sufficiency of the sample. First, three factors were extracted that explained a total variance of 
$75.1 \%$, but only two items were put into the second factor, and one item was put into the third one. In the next stage, the analysis was done to find a single factor. This single factor with an eigen value of 2.652 would explain only $37.9 \%$ of variance and the lowest load factor was 0.306 , while the minimum load factor was higher than 0.5 . The analysis was repeated for the exploration of two factors. The first factor, with an eigen value of $2.652,37.9 \%$ of the variance and the second factor with an Eigen value of 1.426, would explain only $20.4 \%$ of variance (in general, $58.3 \%$ of variance explained). Load factors are shown in Table 6 . As it can be seen in the table, based on the load factor, at least 0.5 of third factor is not loaded into any factor. By reducing the load threshold to 0.4 , this item is placed into the second factor. On the other hand, in both factors, the second and fourth components are loaded. Thus, the first factor can be considered as the general agent, and the second one is the quantitative (yield) sleep factor.

Table 6. Loadings factors Index to explore two factors in components of the Pittsburgh Sleep Quality (PSQI) in depressed patients.

\begin{tabular}{|l|l|l|}
\hline Variable & Primary factor: general quality & Second factor: sleep efficiency \\
\hline The first component & 748.0 & \\
\hline The second component & 519.0 & 597.0 \\
\hline The third component & & 437.0 \\
\hline The fourth component & 610.0 & 672.0 \\
\hline The fifth component & 641.0 & \\
\hline The sixth & 572.0 & \\
\hline The seventh & 787.0 & \\
\hline
\end{tabular}

\section{Discussion}

The aim of this study is to validate the Persian version of the Pittsburgh Sleep Quality Index (PSQI), comparing two different groups of individuals (healthy and depressed patients) by both questionnaire scores of PSQI and ESS measures. Several studies have investigated the relationship between sleep disturbances and depression. Whereas one prospective study showed that people with sleep disturbances are at risk for depression (20), another study has reported that both sleep problems and depression either were connected to each other or two separated diseases with the same etiology (21). Most depressed patients have sleep problems, specially having trouble falling or staying asleep and early morning awakenings (22). Also, there are many depressed patients who frequently complain about increased daytime sleepiness or daytime fatigue (23). Nyer et al.'s study showed that depressed students with sleep disturbance may have more anxiety symptoms, daytime hyperarousal, and functional impairments than depressed students without sleep disturbances (24).

The results of our study showed the internal consistency checks PSQI, in our study, Cronbach's alpha coefficient of the questionnaire to 16 (regardless of Questions 1 and 3) and with regard to coding, questions 2 and 4, was 0.811. With the elimination of the fourth question, this index increased up to 0.821 . The fourth question of PSQI "Your actual sleep during the night?" May be answered differently in different situations, especially which of responding to this question are very widespread in the individuals studied. Therefore, the question must be asked in another way.. Also, the majority of patients, in response to this question, expressed a numerical range such as 5 to 6 hours, and it shows the response of some patients. Asking this question means that the average hours of sleep at night people were surveyed. For questions 1 and 3 as well as the situation was similar in the two questions about the time of arrival to bed and waking up the patients were studied. These questions was difficult to interpret because most patients have not a same comprehension.

In this study, the validity and reliability of the questionnaire were reported as being acceptable. The results of our study showed that the average score of PSQI people surveyed was 8.1 ( $\mathrm{SD}=3.5)$, which was in the range of 1 to 18 , and thus, only $12(12.9 \%)$ received less a score of 5 . The results of our study also showed that average scores on the Beck Depression Inventory (BDI-II) were $27.1(\mathrm{SD}=10.2)$ Epworth sleepiness scale (ESS) $18.0(\mathrm{SD}=3.8)$, respectively. Pearson correlation coefficient between the scores of PSQI and BDI-II was $0.299(0.004=p)$, and the scores of PSQI and ESS were $0.264(0.011=$ p), so there was agreement between the questionnaires. In a study for evaluation the validity of Italian version of PSQI on 50 individuals in five different groups (healthy young and elderly, sleep apnea syndrome patients, depressed patients, individuals with dementia), the results showed an overall reliability coefficient (Cronbach's alpha) of 0.835 , indicating a high degree of internal consistency. The mean PSQI 
global score showed significant differences between groups, with an impaired overall quality of sleep in patients' groups with respect to both the healthy groups and Italian version of PSQI had an overall efficiency comparable to the mother language version and differentiate "good" from "bad" sleepers (25). In Doi et al.'s study, the Japanese version of the Pittsburgh Sleep Quality Index (PSQI-J) was used, and the PSQI-J global and component mean scores were significantly higher in psychiatrically disordered subjects than control subjects, except for the component of sleep duration (26). Results of their study were consistent with our study. Results of our study showed that the correlation coefficients between the PSQI global and component scores were statistically significant. The PSQI global and component mean scores were significantly higher in psychiatrically disordered subjects than control subjects. In study conducted by Yazdi et al., there was a significant correlation between the PSQI and ESS (27). The results obtained from the questionnaire showed ESS, PSQI, and BDI-II double together and have a positive linear correlation. In our study, patients evaluated sleep quality in terms of severity of depression, and, according to the Beck questionnaire, there was a positive linear relationship. The results also showed that the severity of daytime sleepiness and impaired quality of sleep also were correlated strongly. Pearson coefficient showed average scores of people on the Beck Depression Inventory (BDI-II) was $27.1(\mathrm{SD}=10.2)$ and $18.0(\mathrm{SD}=3.8)$ for Epworth Sleep Scale (ESS). These studies examined the factorial structure of PSQI and presented limited support for it. Results of our study showed Pearson correlation coefficient to be $0.299(\mathrm{p}=0.004)$ between PSQI and BDI-II scores and 0.264 $(\mathrm{p}=0.011)$ between PSQI and ESS. To study the factorial structural of PSQI, exploratory factor analysis was used in this study. The results showed that in the PSQI questionnaire, it is possible to regard the first factor as a general one and the second factor as the quantitative agent (yield) of sleep. Studies performed by using the Pittsburgh Sleep Quality Index have some limitations including small sample or heterogeneity in terms of demography, which decrease the researcher's ability in terms of finding research support for all of the sub-scales and generalizing their findings to a larger population. In addition, a review of the literature showed that only a few studies have specifically examined the psychometric properties of this measure (28). However, given the modest sample size of our study, the validity of the results for the PSQI was comparable to or better than that of previous studies.

\section{Conclusions}

In our study, Cronbach's alpha coefficient PSQI questionnaire was up to 0.821. According to the PSQI and BDI-II scores, the results between the PSQI and ESS scores were significantly correlated. Results of our study showed PSQI is a useful, valid, and reliable tool for the assessment of sleep quality, and the Persian version of the questionnaire provides a good and reliable differentiation between normal and pathological groups, with higher scores reported by people characterized by impaired objectively-evaluated sleep quality. The present study supports the utility of the Persian version of PSQI as a reliable and valid measure for subjective sleep quality in clinical practice and research.

\section{Acknowledgments:}

We thank all the participants in this study for generously helping us in this research. We especially thank Dr. Adnan Tizmaghz for his help in editing the manuscript and for constructive criticism of an earlier version of this paper.

\section{Conflict of Interest:}

There is no conflict of interest to be declared.

\section{Authors' contributions:}

All authors contributed to this project and article equally. All authors read and approved the final manuscript.

\section{References}

1) Ford DE, Kamerow DB. Epidemiologic study of sleep disturbances and psychiatric disorders. An opportunity for prevention? JAMA. 1989; 262(11): 1479-84. doi:10.1001/jama.1989.03430110069030. PMID: 2769898

2) Ohayon MM, Reynolds CF 3rd. Epidemiological and clinical relevance of insomnia diagnosis algorithms according to the DSM-IV and the International Classification of Sleep Disorders (ICSD). Sleep Med. 2009; 10(9): 952-60. doi: 10.1016/j.sleep.2009.07.008. PMID: 19748312, PMCID: PMC3715324

3) Yoshino A, Sawamura T, Kobayashi N, Kurauchi S, Matsumoto A, Nomura S. Algorithm-guided treatment versus treatment as usual for major depression. Psychiatry Clin Neurosci. 2009; 63(5): 652-7. doi: 10.1111/j.1440-1819.2009.02009.x. Epub 2009 Aug 10. PMID: 19674382 
4) Eaton WW, Martins SS, Nestadt G, Bienvenu OJ, Clarke D, Alexandre P. The burden of mental disorders. Epidemiol Rev. 2008; 30():1-14. doi: 10.1093/epirev/mxn011. Epub 2008 Sep 19. PMID: 18806255, PMCID: PMC2683377

5) World Health Organization. What are the most effective diagnosis and therapeutic strategies for the management of depression in specialist care? Regional Office for Europe's Health Evidence Network; 2005.

6) Brody DS, Hahn SR, Spitzer RL, Kroenke K, Linzer M, deGruy FV 3rd, Williams JB.Identifying patients with depression in the primary care setting: a more efficient method. Arch Intern Med. 1998; 158(22): 2469-2475. doi:10.1001/archinte.158.22.2469. PMID: 9855385

7) Ohayon MM.Epidemiology of insomnia: what we know and what we still need to learn. Sleep Med Rev. 2002; 6(2): 97-111. doi: http://dx.doi.org/10.1053/smrv.2002.0186. PMID: 12531146

8) Stewart R, Besset A, Bebbington P, Brugha T, Lindesay J, Jenkins R, Singleton N, Meltzer H. Insomnia comorbidity and impact and hypnotic use by age group in a national survey population aged 16 to 74 years. Sleep. 2006 Nov; 29(11):1391-7. PMID: 17162985

9) Naomi B, Roth T, Rosenthal L, Andreski P. Sleep disturbance and psychiatric disorders: A longitudinal epidemiological study of young Adults. Biological Psychiatry. 1996; 39(6): 411-418. doi: http://dx.doi.org/10.1016/0006-3223(95)00188-3. PMID: 8679786

10) DeZee KJ, Hatzigeorgiou C, Kristo D, Jackson JL. Prevalence of and screening for mental disorders in a sleep clinic. J Clin Sleep Med. 2005; 1(2): 136-42. PMID: 17561627

11) Lundt L. Use of the Epworth Sleepiness Scale to evaluate the symptom of excessive sleepiness in major depressive disorder. Gen Hosp Psychiatry. 2005; 27(2): 146-8. doi: http://dx.doi.org/10.1016/j.genhosppsych.2004.10.004. PMID: 15763128

12) Castaneda AE, Tuulio-Henriksson A, Marttunen M, Suvisaari J, Lönnqvist J. A review on cognitive impairments in depressive and anxiety disorders with a focus on young adults. J Affect Disord. 2008; 106(1-2): 1-27. doi: http://dx.doi.org/10.1016/j.jad.2007.06.006. PMID: 17707915

13) Spiegel K, Leproult R, Van Cauter E.Impact of sleep debt on physiological rhythms. Rev Neurol (Paris). 2003 Nov;159(11 Suppl):6S11-20. doi: RN-11-2003-159-S11-0035-3787-101019-ART2. PMID: 14646794

14) Léger D, Bayon V. Societal costs of insomnia. Sleep Med Rev. 2010; 14(6): 379-89. DOI: http://dx.doi.org/10.1016/j.smrv.2010.01.003. PMID: 20359916

15) Buysse DJ, Reynolds CF 3rd, Monk TH, Berman SR, Kupfer DJ. The Pittsburgh Sleep Quality Index: a new instrument for psychiatric practice and research. Psychiatry Res. 1989; 28(2): 193-213. doi: http://dx.doi.org/10.1016/0165-1781(89)90047-4. PMID: 2748771

16) Nazifi, M., Mokarami, H., Akbaritabar, A., Kalte, H. O., \& Rahi, A. Psychometric properties of the persian translation of pittsburgh sleep quality index. Health Scope. 2014; 3(2), 1-4.

17) Izci B, Ardic S, Firat H, Sahin A, Altinors M, Karacan I.Reliability and validity studies of the Turkish version of the Epworth Sleepiness Scale. Sleep Breath. 2008; 12(2): 161-8. PMID: 17922157

18) Sadeghirad B, Haghdoost A, Amin-Esmaeili M, Shahsavand Ananloo E, Ghaeli P, Rahimi-Movaghar A et al. Epidemiology of Major Depressive Disorder in Iran: a Systematic Review and Meta-Analysis. Int J Prev Med. 2010; 1(2): 81-91. PMCID: PMC3075476

19) Sheibani V, Garrusi B, Amirkafi A. Psychometric properties of the Persian version of the Pittsburg Sleep Quality Index addendum for PTSD. Sleep Breath.2009;13(3):259-262. doi: 10.1007/s11325-008-0233-3. PMID: 19023608

20) Roberts RE, Shema SJ, Kaplan GA, Strawbridge WJ. Sleep complaints and depression in an aging cohort: A prospective perspective. Am J Psychiatry. 2000; 157(1): 81-8. PMID: 10618017

21) Staner L. Comorbidity of insomnia and depression. Sleep Med Rev. 2010; 14(1): 35-46. doi: 10.1016/j.smrv.2009.09.003. Epub 2009 Nov 25. PMID:19939713

22) Benca RM. Mood disorders. In: Kryger MH, Roth T, Dement WC, editors. Principles and Practice of Sleep Medicine, Fourth Edition. Philadelphia: Elsevier Saunders; 2005:1311-26.

23) Jaimchariyatam N, Rodriguez CL, Budur K. Prevalence and Correlates of Alpha-Delta Sleep in Major Depressive Disorders. Innov Clin Neurosci. 2011 July; 8(7): 35-49. PMCID: PMC3159543

24) Nyer M, Farabaugh A, Fehling K, Soskin D, Holt D, Papakostas GI et al. Relationship between sleep disturbance and depression, anxiety, and functioning in collegestudents. Depress Anxiety. 2013; 30(9): 10. doi: 10.1002/da.22064. PMCID: PMC3791314

25) Curcio G, Tempesta D, Scarlata S, Marzano C, Moroni F, Rossini PM, Ferrara M, De Gennaro L.Validity of the Italian version of the Pittsburgh Sleep Quality Index (PSQI). Neurol Sci. 2013; 34(4): 511-9. doi: 10.5001/omj.2015.41. PMCID: PMC4459159 
26) Doi Y, Minowa M, Uchiyama M, Okawa M, Kim K, Shibui K, Kamei Y. Psychometric assessment of subjective sleep quality using the Japanese version of the Pittsburgh Sleep Quality Index (PSQI-J) in psychiatric disordered and control subjects.Psychiatry Res. 2000; 27;97(2-3): 165-72. DOI: http://dx.doi.org/10.1016/S0165-1781(00)00232-8. PMID: 11166088

27) Yazdi Z, Sadeghniiat-Haghighi K, Zohal MA, Elmizadeh K. Validity and reliability of the Iranian version of the insomnia severity index. Malays J Med Sci. 2012; 19(4): 31-6. PMID: 23613647, PMCID: PMC3629678

28) Moshkani Farahani D, Tavallaie A, Vahedi E, Rezaiemaram P, Naderi Z, Talaie A. The Relationship between Perceived Sleep Quality, Polysomnographic Measures and Depressive Symptoms in ChemicallyInjured Veterans: A Pilot Study. Iran J Psychiatry. 2014; 9(3): 169-174. PMCID: PMC4277808 